\title{
The placement of nasogastric tubes
}

\section{Malcolm Lemyze MD}

Previously published at www.cmaj.ca

Tracheobronchial aspiration is a potentially life-threatening complication of enteral feeding

A malpositioned nasogastric tube, improper feeding site, large gastric volume and supine position are the main risk factors for aspiration during enteral feeding. When enteral formulations or medications enter the lung through a nasogastric tube inadvertently positioned in the respiratory tract, the lifethreatening complication that results is referred to as "aspiration by proxy" (Figure 1).

Examining aspirate and measuring its $\mathrm{pH}$ may be inconclusive

Aspirate from a tube placed in the stomach is usually grassy green or colourless, with shreds of off-white to tan mucus. The aspirate often has a $\mathrm{pH}$ of 5 or less. In the absence of infection, respiratory secretions are usually clear. However, measuring the $\mathrm{pH}$ level alone does not differentiate between respiratory and gastrointestinal placement of the tube; both sites can have high $\mathrm{pH}$ values (> 6). ${ }^{4}$ The $\mathrm{pH}$ test has no value if the patient is receiving acid suppression medication.

From the Department of Respiratory and Critical Care Medicine, Schaffner Hospital, Lens, France

CMAJ 2010. DOI:10.1503/cmaj.091099

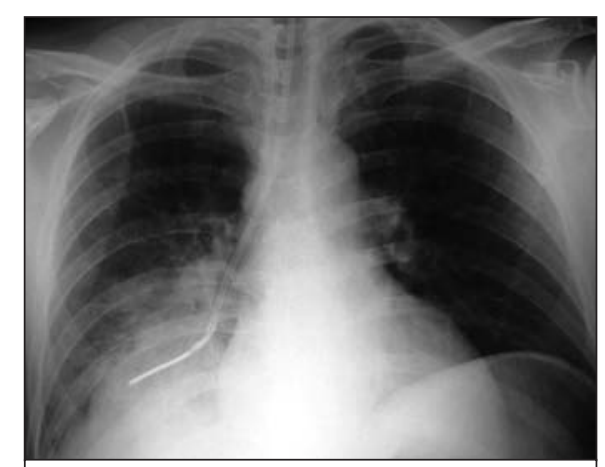

Figure 1: Chest radiography showing misplacement of a nasogastric tube in the right lower lobe of the lung, resulting in extensive pneumonia after enteral feeding.

\section{Other clinical methods of detecting tube placement may be unreliable}

In situations where the patient may have suppressed gag or cough reflexes (e.g., decreased level of consciousness or neurologic debilitation), the absence of coughing or choking after placement of the tube may be misleading. Research continues into simple bedside methods for determining appropriate placement of nasogastric tubes.

Radiography should be used to confirm placement of a nasogastric tube

An abdominal radiograph is considered the "gold standard" for determining the position of a nasogastric tube, especially in a critically ill, elderly, dysphagic or unconscious patient. ${ }^{5}$
Auscultation may not differentiate between respiratory and gastrointestinal placement of a nasogastric tube

Auscultation is most often used at the bedside to check for appropriate placement of a nasogastric tube. Sound generated by air blown through the tube is used to determine tube placement in the gastrointestinal tract. However, a similar gurgling can be heard over the epigastrium when the tube has been incorrectly placed into the tracheobronchial tree, pleural space or esophagus. ${ }^{2,3}$

\section{REFERENCES}

1. Metheny NA. Preventing respiratory complications of tube feedings: evidence-based practice. Am J Crit Care 2006;15:360-9.

2. Metheny N, McSweeney M, Wehrle MA, et al. Effectiveness of the auscultatory method in predicting feeding tube location. Nurs Res 1990;39:262-7.

3. Kearns PJ, Donna C. A controlled comparison of traditional feeding tube verification methods to a bedside, electromagnetic technique. JPEN 2001; 25:210-5

4. Metheny NA, Stewart BJ, Smith L, et al. pH and concentrations of pepsin and trypsin in feeding tube aspirates as predictors of tube placement. JPEN J Parenter Enteral Nutr 1997;21:279-85.

5. American Association of Critical-Care Nurses. Practice alert: verification of feeding tube placement. The Association; 2005. Available: http://classic aacn.org/AACN/practiceAlert.nsf/Files/VOFTP /\$file/Verification\%20of\%20Feeding\%20Tube $\% 20$ Placement\%2005-2005.pdf. (accessed 2009 Nov 24).

This article has been peer reviewed.

Competing interests: None declared.

"Five things to know about ..." is a new series that presents key statements on topics of interest to physicians. For author instructions, go to cmaj.ca. 